\section{Gategory}

Synthesis of Natural

Products and

Potential Drugs

\section{Key words}

communesin $F$

indol-2-one

Diels-Alder cycloaddition

mercuric triflate

trimethyl aluminum
J. BELMAR, R. L. FUNK* (PENNSYLVANIA STATE UNIVERSITY, USA)

Total Synthesis of $( \pm)$-Communesin $\mathrm{F}$ via a Cycloaddition with Indol-2-one

J. Am. Chem. Soc. 2012, 134, 16941-16943.

\title{
Total Synthesis of Communesin F
}

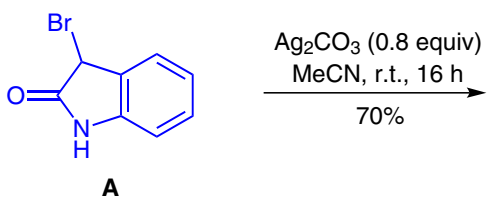

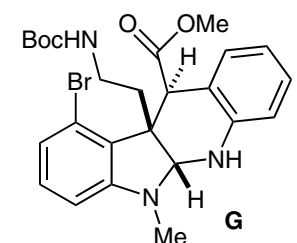<smiles>CCC[AsH3]</smiles>

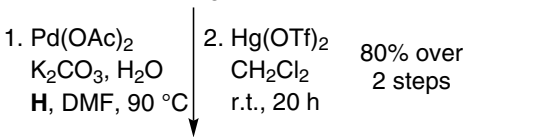
H, DMF, $90^{\circ} \mathrm{C}$ r.t., $20 \mathrm{~h}$

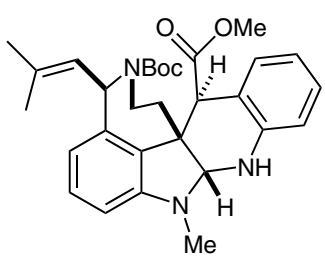

I<smiles>NCCc1c[nH]c2cccc(Br)c12</smiles>
indol-2-one (B)
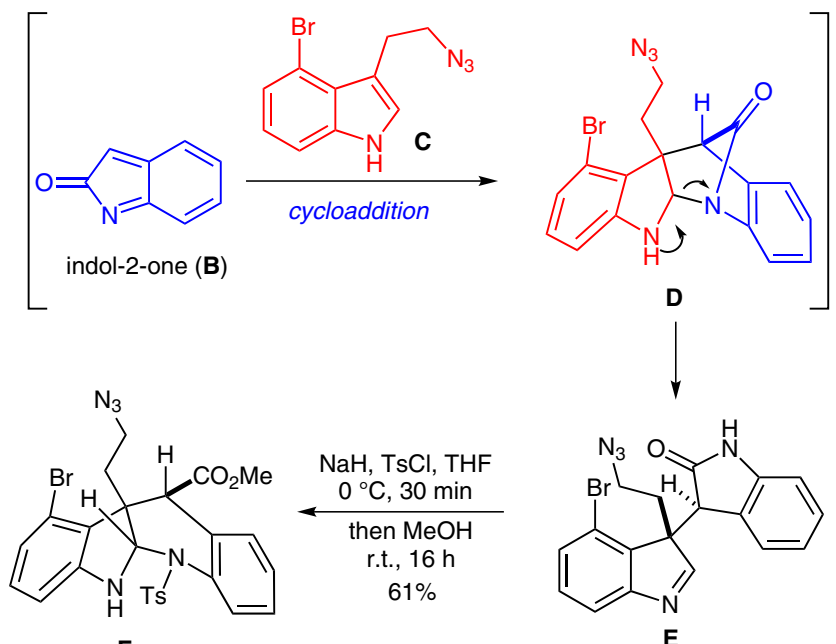<smiles>N#CC[C@]1(c2c(C=N)c(=O)[nH]c3ccccc23)C=Nc2cccc(Br)c21</smiles><smiles>C=CC(C)(C)O</smiles>

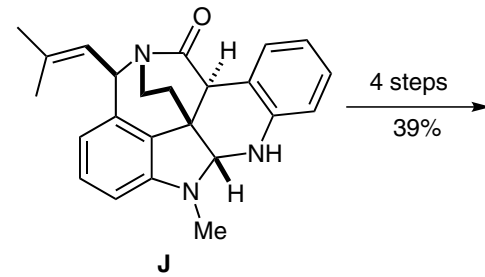<smiles>CC(=O)N1CCC23c4ccccc4NC2(C)N(C)c2cccc(c23)C1C=C(C)C</smiles>

Communesin F
Significance: The stereochemically complex polycyclic structure of the communesins has attracted the interest of several researchers and led to the total syntheses of communesin A, B and F. Funk and co-worker now report an elegant and concise synthesis of the moderately cytotoxic communesin $\mathrm{F}$ that relies on an unusual DielsAlder cycloaddition of indol-2-one, a reaction developed by the group. Its considerable synthetic utility has previously been demonstrated in the total synthesis of perophoramidine and is now further showcased by the synthesis of communesin $\mathrm{F}$ in only 15 steps and an overall yield of $6.7 \%$.
Comment: Indol-2-one B was generated from bromooxindole $\mathbf{A}$ and underwent smooth cycloaddition with indole $\mathbf{C}$ to afford $\mathbf{E}$ via intermediate D. Tosylation of the amide followed by methanolysis led to formation of aminal F. Advanced tetracyclic intermediate $\mathbf{G}$ was obtained in three more steps. Heck reaction of $\mathbf{G}$ with alcohol $\mathbf{H}$, followed by a high-yielding mercuric-triflate promoted cyclization to the benzazepine gave I. Cyclization to the bridged lactam $\mathbf{J}$ could not be achieved under thermal conditions, but exposure to trimethyl aluminum effected the desired transformation. Synthetic communesin F was obtained after four more steps. 